\title{
Direct Coupling of Catharanthine and Vindoline to Provide Vinblastine: Total Synthesis of (+)- and ent-(-)-Vinblastine
}

\author{
Hayato Ishikawa, David A. Colby, and Dale L. Boger ${ }^{\star}$ \\ Department of Chemistry and Skaggs Institute for Chemical Biology, The Scripps Research \\ Institute, 10550 North Torrey Pines Road, La Jolla, California 92037
}

\section{Abstract}

A direct coupling of cantharanthine with vindoline to provide vinblastine is detailed along with key mechanistic and labeling studies. Following an Fe(III)-promoted coupling reaction initiated by generation of a presumed cantharanthine amine radical cation that undergoes a subsequent oxidative fragmentation and diastereoselective coupling with vindoline, addition of the resulting reaction mixture to an $\mathrm{Fe}(\mathrm{III})-\mathrm{NaBH}_{4} /$ air solution leads to oxidation of the $\mathrm{C} 15$ '-C21' double bond and reduction of the intermediate iminium ion directly providing vinblastine (43\%) and leurosidine (23\%), its naturally occurring C21' alcohol isomer. The yield of coupled products, which exclusively possess the natural $\mathrm{C} 16$ ' stereochemistry, approaches or exceeds $80 \%$ and the combined yield of the isomeric $\mathrm{C} 211^{\prime}$ alcohols is $66 \%$.

Vinblastine (1) ${ }^{1}$ is the most widely recognized member of the class of bisindole alkaloids as a result of its clinical use as an antitumor drug. Originally isolated in trace quantities $(0.00025 \%$ of dry leaf weight) from Cantharanthus roseus (L.) G. Don, ${ }^{2}$ its biological properties were among the first to be shown to arise from inhibition of microtubule formation and mitosis that today is still regarded as one of the more successful targets for cancer therapeutic intervention. 3

Presently, the clinical supplies of $\mathbf{1}$ and related drugs $3 \mathrm{c}$ are derived from natural sources. Fortunately, the doses are so small that the production amounts are manageable even with the trace natural abundance of $\mathbf{1}$. Nonetheless, the effort required even for this limited quantity suggests that an efficient synthetic approach might provide a viable alternative. More significantly, an effective synthetic approach would provide access to analogues that incorporate deep-seated structural changes not yet explored. ${ }^{4}$

As a consequence, a number of pioneering studies have defined methods for coupling the lower half, vindoline (2), with appropriate precursors to the upper velbanamine subunit. These include the seminal Potier ${ }^{5}$ and Kutney ${ }^{6}$ disclosures of a coupling protocol enlisting a Polonovski reaction of catharanthine $N$-oxide 3 ) in which its embedded olefin controls the regioselectivity and coupling efficiency of the resulting iminium ion and necessarily provides anhydrovinblastine (4), Scheme 1. Conducting the reaction at low temperature was found to improve the $\mathrm{C} 16^{\prime}$ coupling diastereoselectivity $\left(\geq 5: 1\right.$ at $-78^{\circ} \mathrm{C}$ vs $1: 1$ at $\left.0{ }^{\circ} \mathrm{C}\right),{ }^{4}$ and the subsequent conversion of anhydrovinblastine to vinblastine was addressed by conversion to 7 or with direct generation ${ }^{8}$ of the enamine 6 which in turn was oxidized to the C20' alcohol. This indirect conversion of anhydrovinblastine to vinblastine via the enamine was necessitated

E-mail: boger@scripps.edu.

Supporting Information Available: Full experimental details are provided. This material is available free of charge via the Internet at http://pubs.acs.org. 
by the preferential $\alpha$ versus $\beta$ face delivery of reagents to the $\Delta^{15^{\prime}, 20^{\prime}}$-double bond and the competitive reactivity of $\mathbf{4}$ toward electrophilic reagents required of most olefin oxidation methods. The resulting overall conversions, requiring $8^{7}$ or $5^{8}$ steps, range from $10-40 \%$. Alternative approaches enlisting chloroindolenine intermediates derived from indole C3 electrophilic chlorination of precursors to the velbanamine subunit were slower to develop. Following the disclosures that carbomethoxycleaveamine (7) couples with vindoline to provide the epimeric C16' diastereomer $\mathbf{8}^{, 5,9}$ both Magnus ${ }^{10}$ and Kuehne-Bornmann ${ }^{11}$ described protocols that predominantly, albeit not exclusively, provide the correct $\mathrm{C} 16$ ' diastereomer (Scheme 2). These enlist velbanamine precursors with larger indole-fused ring systems requiring post coupling assemblage of the intact upper subunit. Most recently and based on key observations of Fritz, ${ }^{12}$ Fukuyama disclosed a diastereoselective coupling of an even more advanced and larger ring velbanamine precursor 9 incorporating the $\mathrm{C} 20^{\prime}$ alcohol permitting access to 1 in 4 steps and ca. $50 \%$ overall yield. ${ }^{13}$

With the completion of a first generation total synthesis of vindoline that was extended to a series of related analogues, ${ }^{14}$ we began examining protocols for their incorporation into vinblastine and its analogues. In these studies, we found that a single step biomimetic coupling of catharanthine with vindoline provides 1 directly in yields competitive with the best of the past protocols and that extends our 11-step synthesis of (-)-vindoline ${ }^{14}$ to a 12-step total synthesis of vinblastine. Using improved conditions for a coupling first disclosed and developed by Kutney, 15 treatment of a mixture of catharanthine and vindoline with $\mathrm{FeCl}_{3}(5$ equiv, $23^{\circ} \mathrm{C}$ ), presumably generating the catharanthine amine radical cation which undergoes a subsequent oxidative fragmentation, leads to coupling providing the iminium ion $\mathbf{5}$ exclusively possessing the natural C16' stereochemistry (Scheme 3). Reduction with $\mathrm{NaBH}_{4}$ produces anhydrovinblastine (4) in superb conversion $(90 \%)$ provided $\mathrm{CF}_{3} \mathrm{CH}_{2} \mathrm{OH}$, which solubilizes the reactants, ${ }^{16}$ is used as a cosolvent with the aqueous $0.1 \mathrm{~N} \mathrm{HCl}$ reaction solution. $17 \mathrm{a}$ Moreover, without reductive workup and following a modified oxidation procedure of Sakamoto, ${ }^{18}$ the reaction mixture containing the iminium ion $\mathbf{5}$ can be added to a second $\mathrm{Fe}$ (III) solution $\left(\mathrm{Fe}_{2}(\mathrm{ox})_{3}\right)$ cooled to $0{ }^{\circ} \mathrm{C}$ and saturated with air. Subsequent addition of $\mathrm{NaBH}_{4}$ initiates both reduction of the intermediate iminium ion ${ }^{17 b}$ and selective oxidation of the $\Delta^{15^{\prime}, 20^{\prime}}$-double bond with installation of the $\mathrm{C} 20^{\prime}$ alcohol to provide vinblastine $(\mathbf{1}, 41 \%)$, its naturally occurring $\mathrm{C}^{2} 0^{\prime}$ alcohol isomer leurosidine (21\%), along with anhydrovinblastine $(4,10 \%)$. The yield of coupled material exceeds $75 \%$ with the combined yield of $\mathrm{C} 20$ ' alcohols being $62 \%$ (2:1 $\beta: \alpha$ oxidation). This one-step coupling reaction was conducted to provide natural (+)-vinblastine as well as with synthetic ent-(+)-vindoline ${ }^{14}$ and ent-(-)-cantharanthine to provide ent-(-)-vinblastine $\left([\alpha]_{\mathrm{D}}{ }^{23}-38\left(c 0.05, \mathrm{CHCl}_{3}\right)\right)$. Small improvements in the yield (lutidine: $43 \%$ 1; DBU: $44 \%$ 1) or diastereoselectivity (2,2'-bipyridine: $3: 1)$ have been observed when the oxidation is run in the presence of an organic base suggesting further optimization may be possible.

Although it is conceivable that the $\mathrm{C} 20$ ' oxidation arises from 1,4-reduction of iminium ion 5 followed by enamine 6 oxidation, the oxidation of anhydrovinblastine (4) to $1(50 \%)$ and its C20'-isomer leurosidine (15-20\%) under the $\mathrm{Fe}(\mathrm{III})-\mathrm{NaBH}_{4} / \mathrm{O}_{2}$ conditions without the intermediacy of $5^{17 \mathrm{c}}$ indicate this is not necessary to achieve $\mathrm{C} 20^{\prime}$ hydroxylation. Thus, labeling studies $\left(\mathrm{NaBD}_{4}\right)^{17}$ not only rule out the intermediacy of iminium ion 5 in the conversion of anhydrovinblastine (4) to vinblastine, but they also rule out an Fe-catalyzed isomerization of 4 to enamine 6 and its resulting oxidation (no C21' D incorporation). ${ }^{17 \mathrm{c}}$ Additionally, studies that should promote a 1,4-reduction of iminium ion 5 (e.g. $\mathrm{NaCNBH}_{3}$ ) 7 result in subsequent enamine 6 protonation and reduction, not $\mathrm{C} 20^{\prime}$ oxidation. Finally, reactions run in $\mathrm{D}_{2} \mathrm{O}$ led to no deuterium incorporation, ${ }^{18} \mathrm{O}_{2}$ labeling studies indicate the $\mathrm{C} 20^{\prime}$ alcohol oxygen originates with $\mathrm{O}_{2}$ and not solvent water, reactions run in the absence of $\mathrm{O}_{2}$ led to selective reduction of the $\Delta^{15^{\prime}, 20^{\prime}}$-double bond providing C20'-deoxyvinblastine and its 
C20'-diastereomer $(1: 1.5,67 \%), 17 \mathrm{c}$ and the final oxidation reaction may be conducted on trisubstituted alkenes (e.g., $\beta$-citronellol) that lack an allylic tertiary amine.

Continued studies on the reaction including efforts to improve the $\mathrm{C} 20^{\prime}$-hydroxylation diastereoselectivity are in progress as are its extension to the total synthesis of vinblastine analogues.

\section{Supplementary Material}

Refer to Web version on PubMed Central for supplementary material.

\section{Acknowledgments}

We gratefully acknowledge the financial support of the National Institute of Health (CA115526, CA42056) and the Skaggs Institute for Chemical Biology.

\section{References}

1. Neuss, N.; Neuss, MN. The Alkaloids. Brossi, A.; Suffness, M., editors. 37. Academic; San Diego: 1990. p. 229

2. (a) Noble RL, Beer CT, Cutts JH. Ann. N. Y. Acad. Sci 1958;76:882. [PubMed: 13627916] (b) Noble RL. Lloydia 1964;27:280. (c) Svoboda GH, Nuess N, Gorman M. J. Am. Pharm. Assoc. Sci. Ed 1959;48:659.

3. (a) Owellen RI, Hartke CA, Dickerson RM, Haines FO. Cancer Res 1976;36:1499. [PubMed: 1260766] (b)PearceHLBrossiASuffnessMThe Alkaloids199037145AcademicSan Diego(c) These include vincristine, vindesine, and vinorelbine.

4. Kuehne, ME.; Marko, I. The Alkaloids. Brossi, A.; Suffness, M., editors. 37. Academic; San Diego: 1990. p. 77Review:

5. Potier P, Langlois N, Langlois Y, Gueritte F. J. Chem. Soc., Chem. Commun 1975:670.Langlois N, Gueritte F, Langlois Y, Potier P. J. Am. Chem. Soc 1976;98:7017. [PubMed: 965661]

6. Kutney JP, Ratcliffe AH, Treasurywala AM, Wunderly S. Heterocycles 1975;3:639.Kutney JP, Hibino T, Jahngen E, Okutani T, Ratcliffe AH, Treasurywala AM, Wunderly S. Helv. Chim. Acta 1976;59:2858. [PubMed: 1017976]

7. Mangeney P, Andriamialisoa RZ, Langlois N, Langlois Y, Potier P. J. Am. Chem. Soc 1979;101:2243.

8. Kutney JP, Choi LSL, Nakano J, Tsukamoto H, McHugh M, Boulet CA. Heterocycles 1988;27:1845.

9. Neuss N, Gorman M, Cone NJ, Huckstep LL. Tetrahedron Lett 1968:783.Atta-ur-Rahman. Pak. J. Sci. Ind. Res 1971;14:487.Kutney JP, Beck J, Bylsma F, Cook J, Cretney WJ, Fuji K, Imhof R,

Treasurywala AM. Helv. Chim. Acta 1975;58:1690. [PubMed: 1176300]

10. Magnus P, Stamford A, Ladlow M. J. Am. Chem. Soc 1990;112:8210.Magnus P, Mendoza JS, Stamford A, Ladlow M, Willis P. J. Am. Chem. Soc 1992;114:10232.

11. Kuehne ME, Matson PA, Bornmann WG. J. Org. Chem 1991;56:513.Bornmann WG, Kuehne ME. J. Org. Chem 1992;57:1752.

12. Schill G, Priester CU, Windhovel UF, Fritz H. Tetrahedron 1987;43:3765.

13. Yokoshima S, Ueda T, Kobayashi S, Sato A, Kuboyama T, Tokuyama H, Fukuyama T. J. Am. Chem. Soc 2002;124:2137. [PubMed: 11878966]Kuboyama T, Yokoshima S, Tokuyama H, Fukuyama T. Proc. Natl. Acad. Sci. USA 2004;101:11966. [PubMed: 15141084]

14. Choi Y, Ishikawa H, Velcicky J, Elliott GI, Miller MM, Boger DL. Org. Lett 2005;7:4539. [PubMed: 16178578]Ishikawa H, Elliott GI, Velcicky J, Choi Y, Boger DL. J. Am. Chem. Soc 2006;128:10596. [PubMed: 16895428]

15. (a) Vukovic J, Goodbody AE, Kutney JP, Misawa M. Tetrahedron 1988;44:325. (b) For an analogous electrochemical coupling $\left(0.6 \mathrm{~V}\right.$ in buffer; $\left.\mathrm{NaBH}_{4}\right)$ to provide anhydrovinblastine (4), see: Gunic E, Tabakovic I, Gasic MJ. J. Chem. Soc., Chem. Commun 1993:1496.

16. This cosolvent effect is not large for the vindoline/catharanthine coupling, but is key to its extension to analogue synthesis which will be disclosed in due course. 
17. (a) $\mathrm{NaBD}_{4}$ labeling in the preparation of anhydrovinblastine indicate one D incorporation at $\alpha-\mathrm{C} 21^{\prime}$. (b) $\mathrm{NaBD}_{4}$ labeling for the production of vinblastine from $\mathbf{2}$ and $\mathbf{1 1}$ indicate $\mathrm{D}$ incorporation (two D) at $\alpha-\mathrm{C} 15^{\prime}$ and $\alpha-\mathrm{C} 21^{\prime}$. (c) Oxidation of anhydrovinblastine with $\mathrm{Fe}(\mathrm{III})-\mathrm{NaBD}_{4} / \mathrm{O}_{2}$ leads to a single $\alpha-C 15$ ' D incorporation. In the absence of $\mathrm{O}_{2}$, the reduction leads to two D incorporation at $\alpha-\mathrm{C} 15^{\prime}$ and $\mathrm{C} 20^{\prime}$.

18. Sakamoto N, Tan H, Hata E, Kihara N. Chem. Abstr 1992;117:192139.JP 04164087 
Potier-Langlois

Kutney (1975-1976)

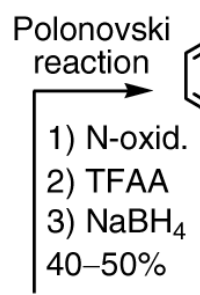

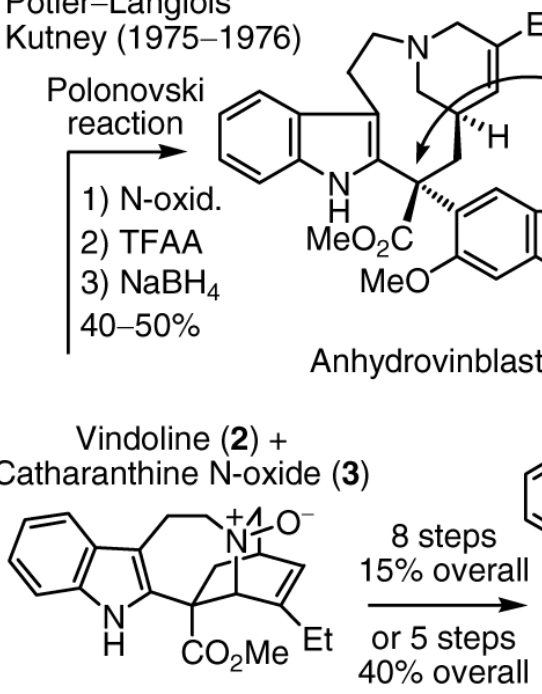

Potier-Langlois (1979)

Vindoline (2) + Catharanthine $\mathrm{N}$-oxide (3)

$1: 1 @ 0{ }^{\circ} \mathrm{C}$ vs $\geq 5: 1 @-78{ }^{\circ} \mathrm{C}$ "H<smiles>C1=CC2CCCCN2C1</smiles>

2) $m-C P B A$

3) TFAA

4) $\mathrm{Tl}(\mathrm{OAC})_{3}$

5) $\mathrm{NaBH}_{4}$ $\mathrm{Me} \mathrm{C}_{2} \mathrm{Me} \downarrow 30 \%$

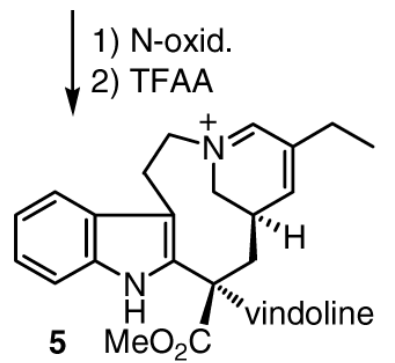

Kutney (1988)<smiles></smiles>

- Requires $\mathrm{C2O}^{\prime} \mathrm{OH}$ introduction (via enamine oxidation)

Scheme 1. 
<smiles>COC(=O)C1C[C@@H]2C=C(I)CN(CCc3c2[nH]c2ccccc32)C1</smiles><smiles>[Mg]O[Te]</smiles>

Kutney (1975)

Potier-Langlois

16'-epi-Anhydrovinblastine<smiles>[B]C1C=C(CC)C[C@](CCCC)(C(C)C)C1</smiles><smiles>CCC1=C[C@@H]2CC(C(C)=O)C3=Nc4ccccc4C3(Cl)CCN(C1)C2</smiles><smiles></smiles>

Magnus (1990)

Kuehne-Bornmann (1992)<smiles>[R][NH+]1CCC2=c3ccccc3=N/C2=C(\C(=O)OC)CC(C[C@]2(CC)COC([R])([R])O2)C1</smiles>

Vindoline

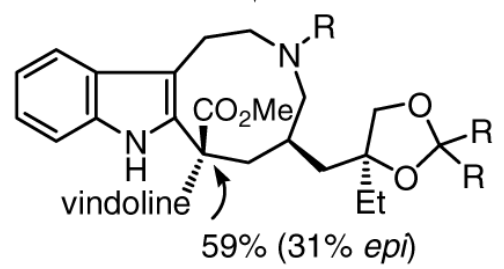

- Fused ring size, stereochem. of ester olefin, \& intermediate that couples (temp.) affect C16' stereochemistry
Fukuyama (2002)

Fritz (1987)

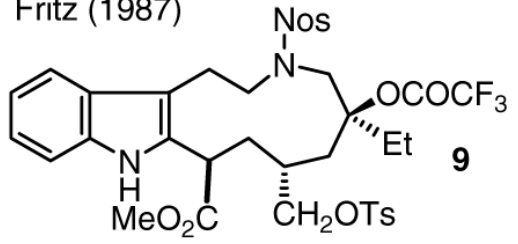

1) $t$-BuOCI 2) TFA, Vindoline

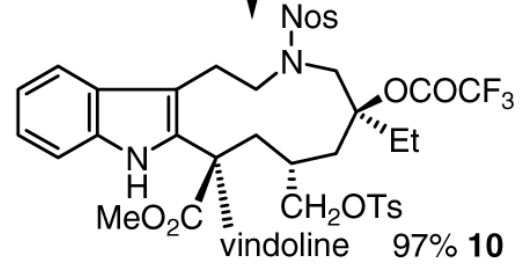

- Correct C16' stereochemistry

- No post coupling C20' OH introduct.

- 3 steps to complete synthesis (50\% overall)

Scheme 2. 


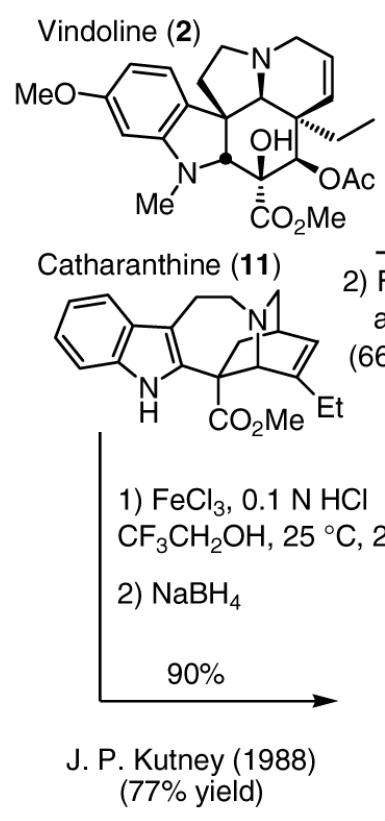

$2: 1$

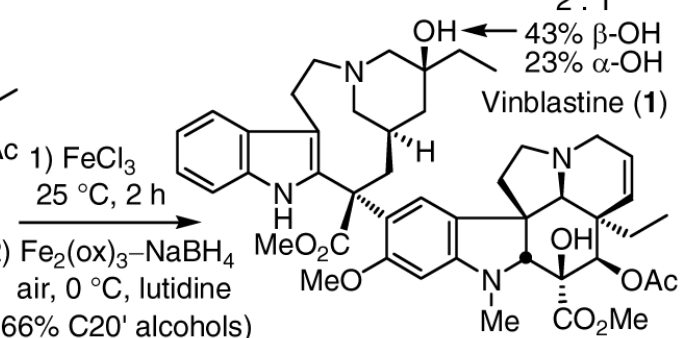

- Single pot without intermediate reduction

1) $\mathrm{FeCl}_{3}, 0.1 \mathrm{~N} \mathrm{HCl}$

Exclusive formation of the natural C16' stereochemistry

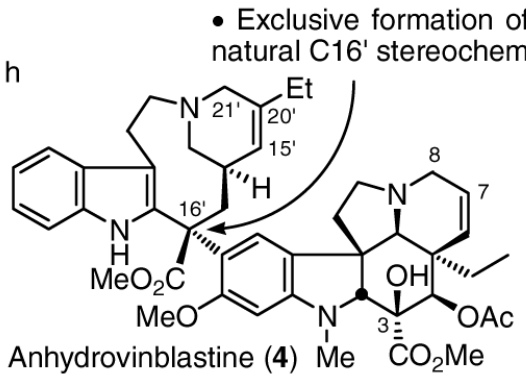

Scheme 3. 